\title{
Qualidade da carne maturada de bovinos Red Norte e Nelore ${ }^{1}$
}

\section{Patrícia Lopes Andrade², Maria Cristina Bressan²,3, Luis Telo da Gama3, Tarcisio de Moraes Gonçalves $^{2}$, Márcio Machado Ladeira², Eduardo Mendes Ramos ${ }^{2}$}

\author{
1 Trabalho financiado pela CAPES e pelo CNPq. \\ 2 Universidade Federal de Lavras, Caixa Postal 3037, CEP: 37200-000 Lavras, MG - Brasil. \\ 3 Instituto Nacional de Recursos Biológicos, Fonte Boa, CEP: 2005-048, Vale de Santarém - Portugal.
}

RESUMO - O objetivo neste trabalho foi avaliar a qualidade da carne do músculo longissimus thoracis de bovinos durante a maturação. Amostras de 22 bovinos Nelore e 22 Red Norte machos, com 24 meses de idade, foram coletadas às 24 horas post mortem, mantidas a $20 \mathrm{C}$ e analisadas aos 1, 7, 14 e 21 dias. Os animais foram terminados em confinamento (112 dias) com silagem de milho (50\%) e concentrado (50\%) à vontade. Os valores de $\mathrm{pH}$ final, perda por cocção, umidade, proteína, gordura e cinzas foram semelhantes entre as amostras de animais Nelore e Red Norte. O teor de vermelho (a*) e a intensidade de amarelo ( $\left.b^{*}\right)$ foram semelhantes entre as carnes dos dois grupos genéticos, porém a luminosidade ( $\mathrm{L}^{*}$ ) foi maior nas amostras de animais Red Norte. A maturação afetou significativamente a luminosidade, o teor de vermelho e amarelo, croma (C*), o ângulo de tonalidade $\left(H^{*}\right)$ e a percepção subjetiva da cor $(\Delta E)$, de forma que as alterações de cor mais importantes ocorreram entre 7 e 14 dias. A força de cisalhamento na carne dos animais Red Norte foi cerca de $0.9 \mathrm{~kg}$ inferior às dos animais Nelore. A maturação influenciou a força de cisalhamento ao longo da maturação e determinou reduções de 1,09; 0,21 e 0,56 kg nos períodos de 1 a 7; 7 a 14 e 14 a 21 dias, respectivamente. O índice de fragmentação miofibrilar foi maior na carne dos animais Red Norte e nas amostras maturadas por 21 dias. A carne dos animais Red Norte apresentou maior luminosidade e maciez. A maturação melhora a maciez das carnes, por reduzir a força de cisalhamento, porém modifica a cor, cujas alterações mais importantes acontecem entre 7 e 14 dias. A escolha do tempo de maturação mais adequado para as carnes bovinas depende do atributo a ser valorizado.

Palavras-chave: cor, força de cisalhamento, índice de fragmentação miofibrilar, perda por cocção, pH, proteína

\section{Aged meat quality in Red Norte and Nellore cattle}

\begin{abstract}
The objective in this study was to evaluate meat quality of longissimus thoracisi muscle during ageing. Samples from 22 Nelore bovines and 22 Red Norte males at 24 months of age were collected at 24 hours post mortem, kept at $2^{\circ} \mathrm{C}$ and analyzed on days $1,7,14$ and 21 . The animals were finished in confinement (112 days) with corn silage (50\%) and concentrate (50\%) ad libitum. Values of final $\mathrm{pH}$, cooking loss, moisture, protein, fat and ash were similar among samples of Nelore and Red Norte animals. The red level $\left(a^{*}\right)$ and the yellow intensity (b*) were similar among meats of the two genetic groups, however, luminosity $\left(\mathrm{L}^{*}\right)$ was higher in samples of Red Norte animals. Ageing significantly affected luminosity, level of red and yellow, chroma, tone angle $\left(H^{*}\right)$ and subjective perception of the color $(\Delta E)$, thus, the most important changes in color occurred from 7 to 14 days. Shear force in the meat of Red Norte animals was approximately $0.9 \mathrm{~kg}$ lower than in Nelore animals. Ageing influenced shear force during maturation with a reduction of $1.09 \mathrm{~kg}, 0.21 \mathrm{~kg}$ and $0.56 \mathrm{~kg}$ in the periods from 1 to 7 , from 7 to 14 and from 14 to 21 days, respectively. The myofibrillar fragmentation index was higher in the meat of Red Norte animals and in samples aged for 21 days. The meat of Red Norte animals showed more tenderness and luminosity. Ageing improves the tenderness of meat because it reduces shear force, however, it changes the color, whose most important changes take place from 7 to 14 days. The choice of the most appropriate ageing time for beef depends on which attribute will be considered.
\end{abstract}

Key Words: color, cooking loss, miofibrilar fragmentation index, $\mathrm{pH}$, protein, shear force

\section{Introdução}

O Brasil é o maior exportador de carne bovina, com um rebanho comercial estimado em 207,2 milhões de animais (IBGE, 2007), sendo mais de $80 \%$ do tipo B. indicus
(Mariante et al., 2003). A expansão desse rebanho é resultado da adaptação às regiões de clima quente, onde esses animais mostram taxas altas de conversão alimentar, ganho de peso, precocidade, fertilidade, resistência a parasitoses e tolerância ao calor (Ferreira \& Cardoso, 1993). Em contrapartida, a 
carne dos B. indicus apresenta menor maciez do que a dos B. taurus (Wheeler et al., 1990) e, à medida que a proporção de $B$. indicus aumenta num cruzamento, ocorre redução na maciez da carne (Rubensam et al., 1998). A diferença na força de cisalhamento entre carnes provenientes de $B$. taurus e B. indicus é atribuída ao comportamento do complexo calpaínas/calpastatina durante a maturação (Shackelford et al., 1994), em que as calpaínas rompem parcialmente os miofilamentos, tornando a carne mais macia (Muroya et al., 2006). Entretanto, a atividade catalítica dessas enzimas é inibida pela calpastatina (Koohmaraie et al., 2002), cuja atividade em músculos de animais $B$. indicus, é mais intensa que em $B$. taurus (Rubensam et al., 1998).

Os cruzamentos entre $B$. taurus e $B$. indicus visam a exploração da complementaridade entre raças e o benefício da heterose (Gama, 2002). Por vezes opta-se pela utilização de raças compostas, que combinam as características das raças intervenientes, havendo contudo menor utilização da complementaridade entre raças e um nível de heterose mais reduzido. A raça Red Norte é uma raça composta, de formação recente, desenvolvida com contribuição das raças Nelore, Tabapuã, Red Angus, Santa Gertrudis e Senepol, e o seu comportamento produtivo, nomeadamente nas características de qualidade de carne, não é conhecido.

O objetivo neste trabalho foi avaliar a evolução das características de qualidade da carne no músculo longissimus thoracis de bovinos Nelore e Red Norte submetido à maturação $\left(2^{\circ} \mathrm{C}\right)$ por $1,7,14$ e 21 dias .

\section{Material e Métodos}

O material experimental foi formado por 44 bovinos machos não-castrados com média de 24 meses de idade, sendo 22 da raça Nelore, com peso vivo médio inicial de 482 kg e 22 do composto Red Norte, com peso vivo médio inicial de $519 \mathrm{~kg}$.

Os animais foram criados a pasto na região de Três Pontas, Minas Gerais, com pastagem cultivada (Brachiaria brizantha, Brachiaria decumbens, Brachiaria humidicula) e terminados em sistema de confinamento por 112 dias, no Departamento de Zootecnia da Universidade Federal de Lavras, no período de maio a setembro de 2007. Na fase de terminação, os bovinos foram alocados em baias coletivas, 11 animais por baia, com área de $30 \mathrm{~m}^{2}$ e separados de acordo com o agrupamento genético.

A dieta foi calculada e balanceada para atender às exigências previstas no NRC (2000) (Tabela 1) e fornecida ad libitum em forma de ração completa, duas vezes ao dia.
O embarque, transporte e desembarque dos animais ocorreu às 8,9 e 10 horas da manhã. $O$ transporte foi realizado em caminhão boiadeiro, adaptado para o transporte de bovinos, com capacidade de 22 animais por caminhão e a distância percorrida foi de $60 \mathrm{~km}$. No frigorífico, durante o pré-abate, os animais foram submetidos a jejum de sólidos e dieta hídrica por 24 horas em currais sem cobertura, local onde receberam banhos periódicos, com chuveiros de aspersão, visando um maior conforto térmico.

As operações de abate foram realizadas em frigorífico industrial sob Inspeção Federal (SIF 1663) e as operações de abate foram executadas segundo as recomendações do RIISPOA (BRASIL, 1952): com insensibilização mecânica (método percussivo, utilizando pistola pneumática); estimulação elétrica na fase final da sangria; e resfriamento das carcaças em câmara fria, a $4^{\circ} \mathrm{C}$, por 24 horas.

As amostras do músculo longissimus thoracis foram coletadas às 24 horas post mortem entre a $10^{\text {a }}$ e $12^{\text {a }}$ costelas nas duas meias-carcaças. De cada meia-carcaça foram retiradas quatro amostras (bifes de $2,5 \mathrm{~cm}$ de espessura), seccionadas no sentido transversal do músculo. Os bifes foram identificados individualmente e embalados a vácuo em filme de polietileno termoencolhível de alta resistência. As amostras das meias-carcaças direitas foram usadas para determinar a composição centesimal (umidade, proteína, extrato etéreo e cinzas) e as amostras das meias-carcaças esquerdas foram usadas para o estudo de maturação. Cada uma das quatro amostras coletadas por animal foi maturada por 1, 7, 14 ou 21 dias e submetida às análises de cor, perda por cocção, força de cisalhamento e índice de fragmentação miofibrilar.

Tabela 1 - Ingredientes da dieta e composição da dieta experimental

\begin{tabular}{lc}
\hline Ingrediente & Composição (\%) \\
\hline Silagem de milho & 50,0 \\
Milho integral moído & 23,0 \\
Polpa cítrica & 11,5 \\
Farelo de soja & 10,0 \\
Farelo de algodão & 3,4 \\
Ureia & 0,5 \\
Núcleo mineral & 1,6 \\
Nutriente & \\
Matéria seca $^{2}$ & 47,7 \\
Proteína bruta $^{3}$ & 14,3 \\
Fibra em detergente neutro $^{3}$ & 30,1 \\
Carboidratos não fibrosos $^{3}$ & 47,9 \\
Extrato etéreo $^{3}$ & 3,0 \\
Nutrientes digestíveis totais $^{3,4}$ & 70,3 \\
\hline
\end{tabular}

${ }^{1}$ Níveis de garantia por quilo do produto: Ca - 235 g; P - 45 g; S - 23 g; Na - 80,18 g; Zn - 2,38 mg; Cu - 625 mg; Fe -1,18 mg; Mn - 312 mg: Co - 32 mg; I - 41,6 mg;

Se - 11,25 mg; vit. A - 70.000 UI; vit. D3 - 5.000 UI; vit. E - 15 UI; niacina - 3,33 mg.

2 Base da matéria natural.

3 Base da matéria seca.

${ }^{4}$ Calculado segundo o NRC (2000). 
As amostras (bifes) para a maturação, provenientes dos 44 animais amostrados, foram estocadas à temperatura constante de $2^{\circ} \mathrm{C}$, em estufa com controle de temperatura automático MA 415 (Marconi Equipamentos Ltda., Piracicaba, Brasil), e os 4 bifes de cada carcaça foram distribuídos aleatoriamente nos quatro tempos de avaliação: $1,7,14$ e 21 dias post mortem.

$\mathrm{O} \mathrm{pH}$ final foi determinado às 24 horas post mortem no músculo longissimus thoracis, na altura da $12^{\text {a }}$ costela, com auxílio do potenciômetro digital portátil M1120x, (Mettler-Toledo International Inc., Columbus, EUA), equipado com eletrodo de inserção com resolução de 0,01 unidades de $\mathrm{pH}$. Duas leituras de $\mathrm{pH}$ foram obtidas para cada carcaça e o valor médio foi utilizado na análise estatística.

A determinação da luminosidade ( $\mathrm{L}^{*}$ ), teor de vermelho (a*) e de amarelo (b*) 1, 7, 14 e 21 dias post mortem foi realizada após a retirada das peças das embalagens e da exposição por 30 minutos à mistura dos gases atmosféricos. Nas superfícies das fatias, foram determinados a luminosidade, o teor de vermelho e o teor de amarelo, de acordo com o sistema CIE, usando o colorímetro Chroma-Meter Cr-200b (Minolta Camera Co., Ltd., Osaka, Japan), iluminante D65, $10^{\circ}$ graus para observação padrão, calibrado para um padrão branco. Em virtude da ampla variação nos resultados individuais para as coordenadas de cor decorrentes da presença de gordura intramuscular e tecido conjuntivo, nove leituras foram realizadas por fatia e as médias foram utilizadas na análise estatística.

As determinações dos valores para croma ( $\left.\mathrm{C}^{*}\right)$, ângulo de tonalidade $\left(H^{*}\right)$ e percepção subjetiva da diferença de cor $(\Delta E)$ foram feitas de acordo com MacDougal (1994), usando as coordenadas luminosidade $\left(\mathrm{L}^{*}\right)$, teor de vermelho (a*) e intensidade de amarelo (b*) obtidas nas determinações colorimétricas, com as seguintes fórmulas:

$$
\begin{aligned}
& \mathrm{C}^{*}=\left(\left(\mathrm{a}^{*}\right)^{2}+\left(\mathrm{b}^{*}\right)^{2}\right)^{0,5} ; \\
& H^{*}=\arctan \left(\mathrm{b}^{*} / \mathrm{a}^{*}\right) ; \\
& \Delta E=\left(\Delta \mathrm{L}^{2}+\Delta \mathrm{a}^{2}+\Delta \mathrm{b}^{2}\right)^{0,5} .
\end{aligned}
$$

As amostras maturadas por períodos de 1, 7, 14 e 21 dias, após a análise de cor, foram submetidas à retirada da gordura superficial da peça e foram pesadas individualmente em balança eletrônica semi-analítica. As peças, identificadas, foram colocadas em forno elétrico comercial equipado com termômetros individuais (Tedesco Ltd., Caxias do Sul, Brasil), pré-aquecido a $180^{\circ} \mathrm{C}$ até atingirem a temperatura interna individual de $70^{\circ} \mathrm{C}$, resfriadas à temperatura ambiente e foram novamente pesadas. A diferença entre o peso inicial e final da cada bife, expressa percentualmente, correspondeu à perda de peso por coç̧ão por animal nos tempos de 1, 7, 14 e 21 dias.

As amostras usadas na determinação da perda de peso por cocção foram embaladas em polietileno e refrigeradas por 24 horas a $4^{\circ} \mathrm{C}$, para determinação da força de cisalhamento. De cada bife foram retiradas 8 a 12 sub-amostras na forma de cilindros, com diâmetro de $1 / 2$ polegada, no sentido paralelos às fibras musculares, conforme Wheeler et al. (1995). A força de cisalhamento foi medida individualmente, de forma que cada cilindro foi colocado no sentido perpendicular às fibras musculares na célula Warner-Bratzler com lâmina de 1,016 mm, acoplada ao texturômetro MTA.TX.plus (Stable Micro Systems Ltd., Vienna Court, UK), com capacidade para $50 \mathrm{~kg}$, utilizando o programa Texture Expert. O texturômetro foi calibrado para: velocidade do teste de 200 $\mathrm{mm} / \mathrm{min}$; velocidade pós-teste de $2400 \mathrm{~mm} / \mathrm{min}$; distância de $40 \mathrm{~mm}$; peso de calibração de $10 \mathrm{~kg}$. A força máxima foi registrada, para cada cilindro, na curva do programa Texture Expert e as médias dos valores dos cilindros por carcaça nos tempos de 1, 7, 14 e 21 dias foram usadas na análise estatística.

As amostras para análise do índice de fragmentação miofibrilar foram coletadas às 24 horas post mortem e aos 21 dias, e imediatamente analisadas. Esta determinação foi realizada de acordo com os procedimentos de Culler et al. (1978), em amostras do músculo longissimus thoracis, livres de gordura e do excesso de tecido conjuntivo. A concentração de proteína da solução de miofibrilas foi determinada pelo método do biureto (Gornall et al., 1949). A diluição $(0,5 \mathrm{mg} / \mathrm{mL})$ em um volume final de $8 \mathrm{~mL}$ foi usada para a determinação do índice de fragmentação miofibrilar. A absorbância a $540 \mathrm{~nm}$ foi medida em espectrofotômetro digital M SP-22 (Agilent Technologies Inc., Palo Alto, CA, USA). O índice do índice de fragmentação miofibrilar foi calculado de acordo com Culler et al. (1978), em que a absorbância encontrada a $540 \mathrm{~nm}$ foi multiplicada pela constante 200 e o resultado foi expresso em unidades. As análises foram realizadas em duplicata e a média foi usada na análise estatística.

As amostras para as análises da composição centesimal foram congeladas às 24 horas post mortem, mantidas a $-18^{\circ} \mathrm{C}$ e, para a análise, foram descongeladas a $4^{\circ} \mathrm{C}$ por 24 horas. A gordura superficial do músculo foi previamente removida e a amostra foi homogeneizada individualmente usando o triturador TE 102 (Tecnal Equip. para Laboratórios, Piracicaba, BR), até obtenção de uma massa homogênea.

A metodologia para a determinação da composição centesimal seguiu os protocolos da AOAC (1995), em que a proteína bruta foi quantificada pela análise de nitrogênio pelo método micro Kjeldahl, utilizando bloco digestor TE 007D (Tecnal Equip. p/ Laboratórios, Piracicaba, BR) e destilador de nitrogênio TE 036/1 (Tecnal Equip. para Laboratórios, Piracicaba, BR), a gordura (extrato etéreo) foi extraída pelo método Soxhlet, com auxílio do extrator Soxhlet 
TE - 044-81/50 (Tecnal Equip. p/ Laboratórios, Piracicaba, BR); a umidade foi determinada em estufa TE 394/2 (Tecnal Equip. p/ Laboratórios, Piracicaba, BR) a $105^{\circ} \mathrm{C}$ até peso constante e as cinzas foram determinadas por incineração em mufla M15-200-3 (Ind. Com. Fornos Magnus Ltda, Belo Horizonte, BR) a $550^{\circ} \mathrm{C}$. As análises foram realizadas em duplicata e a média foi utilizada na análise estatística. Os resultados foram expressos em percentuais da matéria integral.

O delineamento estatístico foi inteiramente casualizado, em esquema fatorial $2 \times 4$, com dois agrupamentos genéticos (Red Norte e Nelore), e avaliados em quatro tempos de maturação (1, 7, 14 e 21 dias) quanto às características de cor ( $\mathrm{L}^{*}, \mathrm{a}^{*}, \mathrm{~b}^{*}, \mathrm{C}^{*}, H^{*} \mathrm{e} \Delta E$ ), perda de peso por coç̧ão e força de cisalhamento, sendo em cada momento avaliadas as 44 unidades experimentais. As análises de $\mathrm{pH}$, umidade, proteína, gordura e cinzas foram avaliadas no $1^{\circ}$ dia, e a análise do índice de fragmentação miofibrilar foi realizada aos 1 e 21 dias post mortem.

Os dados foram analisados com o PROC GLM do SAS (SAS Institute, 2004), considerando os efeitos fixos da raça e tempo de maturação e a respectiva interação. Nos casos em que a interação não foi significativa, esta foi retirada do modelo, que passou a incluir apenas os efeitos principais do grupo genético e tempo de maturação. As médias ajustadas (LSMeans) obtidas para os grupos genéticos, tempos de maturação ou para as respectivas combinações, foram comparadas pelo teste LSD do PROC GLM do SAS, utilizando um nível de significância de 5\%. As correlações entre variáveis foram estimadas com o PROC CORR do SAS (SAS Institute, 2004). A evolução da força de cisalhamento ao longo da maturação foi estimada para cada raça, usando uma função logarítmica do dia de maturação.

\section{Resultados e Discussão}

As médias de $\mathrm{pH}$ e dos componentes da análise centesimal do músculo longissimus thoracis não foram influenciadas $(\mathrm{P}>0,05)$ pelo grupo genético (Tabela 2$)$.

Tabela 2 - pH (24 horas) e composição centesimal do músculo longissimus thoracis de bovinos dos grupos genéticos Red Norte e Nelore, em porcentagem da matéria integral

\begin{tabular}{lrr}
\hline Variável & \multicolumn{1}{c}{ Nelore } & \multicolumn{1}{c}{ Red Norte } \\
\hline pH final & $5,48 \pm 0,01$ & $5,48 \pm 0,01$ \\
Umidade & $74,59 \pm 0,18$ & $75,11 \pm 0,19$ \\
Proteína & $22,02 \pm 0,33$ & $21,77 \pm 0,34$ \\
Gordura & $2,40 \pm 0,17$ & $2,13 \pm 0,17$ \\
Cinzas & $0,99 \pm 0,01$ & $0,99 \pm 0,01$ \\
\hline
\end{tabular}

As médias de $\mathrm{pH}$ encontradas no presente estudo situam-se no intervalo entre 5,4 a 5,8, que são valores considerados adequados na manutenção da vida de prateleira (Mach et al., 2008). O pH final ou a acidificação corresponde ao acúmulo de ácido lático oriundo da ressíntese do ATP a partir da glicose proveniente das reservas de glicogênio (Pösö \& Puolanne, 2005). Normalmente bovinos suplementados com grãos possuem maior disponibilidade de glicogênio no momento do abate e menor pH final da carne (Neath et al., 2007). Muchenjea et al. (2009) descrevem que valores baixos de pH são também decorrentes de animais mantidos em condições pré-abate de bem estar animal. Assim, possivelmente, os valores médios encontrados no presente trabalho (próximos ao limite mais baixo considerado adequado), sejam reflexo da dieta (suplementação com grãos), associada às condições ante mortem adequadas. Por outro lado, valores baixos de pH são relacionados com menor atividade das enzimas proteolíticas e menor maciez da carne, uma vez que as calpaínas $\mu$ e m apresentam $\mathrm{pH}$ ótimo em valores próximos a 7 (Béltran et al., 1997). Kanawa \& Takahashi (2002) descrevem ainda que a $\mu$-calpaína é inativada em carnes com $\mathrm{pH}$ entre 5,5 a 5,8 no post mortem. Considerando essas informações, os valores de $\mathrm{pH}$ encontrados no presente trabalho poderiam anular o processo de maturação, de forma a não haver reduções na força de cisalhamento ao longo do processo de maturação.

Com relação à ausência do efeito do grupo genético nos valores de $\mathrm{pH}$ final, outros autores também descrevem esse comportamento, tais como: Whipple et al. (1990) em carnes de animais B. taurus e B. taurus $\times B$. indicus (Hereford $\times$ Angus, $3 / 8$ Sahiwal e $5 / 8$ Sahiwal), cuja média geral foi de 5,5; Vieira et al. (2007) em animais B. taurus (Brown Swiss, Limousin e Asturiana de los Valles), com médias variando de 5,59 a 5,79; e Silveira et al. (2006), que encontraram resultados similares de $\mathrm{pH}$ entre animais Aberdeen Angus e Nelore × Aberdeen Angus (5,54 e 5,53, respectivamente). Entretanto, Wheeler et al. (1990) observaram menor $\mathrm{pH}$ em Hereford quando comparado ao Brahman e justificaram esses resultados em função da maior gordura de cobertura nos animais Hereford. Por outro lado, os animais $B$. indicus mostram temperamento mais agitado do que os B. taurus (Silveira et al., 2006) e isso poderia resultar em diferenças no $\mathrm{pH}$ final entre as carcaças de Nelore e as carcaças de animais Red Norte, o que não se verificou neste estudo.

As médias de umidade, proteína, gordura e cinzas foram semelhantes $(\mathrm{P}>0,05)$ para as amostras de Red Norte e Nelore (Tabela 2). Na análise centesimal, a gordura é o componente que apresenta maior variação (Williams et al., 1983) e, 
normalmente, as quantidades depositadas resultam do balanço entre energia da dieta e requerimentos metabólicos (Eriksson \& Pickova, 2007). Na literatura, os resultados da análise centesimal que comparam animais $B$. indicus com B. taurus são contraditórios. Crouse et al. (1989) encontraram menor quantidade de gordura e menor marmorização em carnes de animais de raças $B$. indicus. Outros autores descrevem mais gordura intramuscular em $B$. indicus, como Moreira et al. (2003) em animais puros (1,86\%) quando comparados a animais cruzados $B$. indicus $\times B$. taurus (1,37\%) e Vaz et al. (2001) quando confrontados animais Nelore (2,23\%) e cruzados Nelore $\times$ Charolês (1,97\%). Por outro lado, em trabalhos recentes com animais puros terminados com grãos (Rossato et al., 2009) ou pasto (Rossato et al., 2010), foi observado que B. taurus e B. indicus mostram amplas variações nas quantidades de gordura em função da dieta (próximo a 5\% na materia integral). Entretanto, em ambos trabalhos, a gordura foi semelhante entre grupos genético. No presente estudo, a ausência do efeito dos grupos genéticos pode ser justificada pelas possíveis semelhanças, entre estes animais, nas taxas de ingestão e requerimento de nutrientes.

Os resultados de cor, perda de peso por cocção, força de cisalhamento e índice de fragmentação miofibrilar não mostraram interação significativa $(\mathrm{P}>0,05)$ entre os fatores grupo genético e dias de maturação. Os valores médios das amostras de Nelore e Red Norte para as coordenadas de cor a* e b*, bem como para $C^{*}, H^{*}$ e $\Delta E$ foram semelhantes $(\mathrm{P}>0,05)$ e somente a média de luminosidade foi significativamente $(\mathrm{P}<0,05)$ mais elevada em Red Norte (Tabela 3). Porém, o tempo de maturação afetou significativamente $(\mathrm{P}<0,05)$ todas as coordenadas de cor $\mathrm{e}$ os valores de $C^{*}, H^{*}$ e $\Delta E$.

A ausência do efeito do grupo genético na coloração também foi relatada por Silveira et al. (2006) em amostras de Aberdeen Angus e Nelore $\times$ Aberdeen Angus com médias semelhantes de luminosidade, a*, b* e $H^{*}$, e por Vieira et al. (2007) em animais Brown Swiss, Limousin e Asturiana de los
Valles, com médias semelhantes de luminosidade, a* e b*. Por outro lado, os resultados indicam menor luminosidade nas carnes de animais Nelore quando comparadas aos Red Norte, o que concorda com os achados de Voisinet et al. (1997), que verificaram em bovinos com temperamento mais excitável carnes mais escuras ao corte. De modo geral, as médias de luminosidade encontradas nas carnes de ambos os grupos genéticos foram baixas, demonstrando que essas carnes eram mais escuras que as médias normalmente descritas. Os fatores que influenciam a luminosidade das carnes, relatados na literatura, são dieta, idade, atividade física desenvolvida pelos animais em vida, quantidade de pigmentos de cor, quantidade de gordura e $\mathrm{pH}$ final (Muchenjea et al., 2009). Neste trabalho, os animais utilizados eram não-castrados, que, conforme descrito por Rodrigues \& Andrade (2004), têm carnes com menor luminosidade em comparação à de animais castrados, possivelmente em razão da menor quantidade de gordura intramuscular.

As três coordenadas de cor mostraram evoluções ao longo do tempo de maturação, uma vez que houve aumento nas médias de luminosidade, teores de vermelho e amarelo, C* e $H^{*}$. Quando avaliadas as médias, observou-se que: a) a luminosidade, o teor de vermelho e o croma diferiram significativamente $(\mathrm{P}<0,05)$ entre os dias 1,7 , e 14 , mas entre 14 e 21 dias as médias foram semelhantes; b) o teor de amarelo e o ângulo $H^{*}$ diferiram entre os dias 1, 7, 14 e 21 . Os resultados de cor demonstraram que para luminosidade, a* e C* as modificações importantes de cor ocorrem sobretudo no período entre 1 , 7 e 14 dias; e que para b* e $H^{*}$ as modificações de cor são significativas ao longo de todo o período estudado.

A luminosidade e os teores de vermelho e amarelo na carne retratam a luminosidade, que é influenciada pela quantidade de água da superfície da peça, consequência da capacidade de retenção de água (Purchas, 1990), a quantidade de gordura (Cañeque et al., 2003) e a quantidade de pigmento de cor (Muchenjea et al., 2009); o teor de vermelho, que reflete as quantidades de pigmento vermelho

Tabela 3 - Características de cor, perda de peso por cocção , força de cisalhamento e índice de fragmentação miofibrilar do músculo longissimus thoracis de bovinos Red Norte e Nelore

\begin{tabular}{|c|c|c|c|c|c|c|c|c|}
\hline \multirow[t]{2}{*}{ Variável } & \multicolumn{2}{|c|}{ Grupo genético } & \multirow[t]{2}{*}{ EP } & \multicolumn{4}{|c|}{ Dia de maturação } & \multirow[t]{2}{*}{ EP } \\
\hline & Nelore & Red Norte & & 1 & 7 & 14 & 21 & \\
\hline Luminosidade & $33,74 a$ & $34,60 b$ & 0,21 & $28,80 \mathrm{a}$ & $30,67 b$ & $38,25 c$ & $38,95 c$ & 0,30 \\
\hline Teor de vermelho & $16,63 a$ & $16,76 a$ & 0,15 & $13,54 \mathrm{a}$ & $14,64 b$ & $19,32 c$ & $19,29 c$ & 0,21 \\
\hline Teor de amarelo & $3,78 a$ & $3,99 a$ & 0,14 & $1,56 a$ & $2,58 b$ & $5,34 c$ & $6,07 d$ & 0,20 \\
\hline Croma & $17,13 a$ & $17,32 \mathrm{a}$ & 0,17 & $13,66 \mathrm{a}$ & $14,88 b$ & $20,07 c$ & $20,29 c$ & 0,23 \\
\hline Ângulo de tonalidade & $11,96 a$ & $12,49 a$ & 0,38 & $6,55 a$ & $9,88 b$ & $15,34 \mathrm{c}$ & $17,13 d$ & 0,53 \\
\hline Perdas por cocção (\%) & $29,17 \mathrm{a}$ & $29,21 \mathrm{a}$ & 0,45 & $28,97 \mathrm{ab}$ & $28,58 a$ & $30,53 b$ & 28,67 a & 0,63 \\
\hline Força de cisalhamento (kg) & $4,27 a$ & $3,40 \mathrm{~b}$ & 0,10 & $4,90 \mathrm{c}$ & $3,81 b$ & $3,60 \mathrm{~b}$ & $3,04 \mathrm{a}$ & 0,14 \\
\hline Índice de fragmentação miofibrilar & $65,71 \mathrm{a}$ & $78,48 b$ & 2,30 & $60,18 \mathrm{a}$ & - & - & $84,01 b$ & 2,30 \\
\hline
\end{tabular}

Médias seguidas de mesma letra, na mesma linha, dentro de grupo genético ou dia de maturação, não diferem entre si pelo teste LSD a 5\%. 
das mioglobinas e dos citocromos C (Hedrick et al., 1983); e o teor de amarelo, que é associado à composição de carotenoides (Priolo et al., 2001). Em trabalho de revisão, Muchenjea et al. (2009) descrevem que, em bovinos, as médias de luminosidade variam entre 33,2-41,0, as médias de a* entre 11,1-23,6 e as médias de b* entre 6,1-11,3. Em bovinos jovens, Abularach et al. (1998) classificaram carnes escuras quando $L^{*} \leq 29,68$, e carnes claras quando $L^{*} \geq 38,51$; em relação à intensidade de vermelho, consideraram a* $\leq 14,83$ como baixa e $a^{*} \geq 29,27$ como alta; e para a intensidade de amarelo, $b^{*} \leq 3,40$ como baixa e $b^{*} \geq 8,28$ como alta.

Neste trabalho, as médias de nos dias 1 e 7 foram mais baixas do que as médias relatadas por Muchenjea et al. (2009) e podem ser consideradas como carnes escuras (Abularach et al., 1998). O teor médio de vermelho situouse entre os valores citados por Muchenjea et al. (2009), mas foram consideradas com baixa intensidade de vermelho aos dias 1 e 7, segundo as descrições de Abularach et al. (1998). Entretanto, as médias de luminosidade e teor de vermelho aos 14 e 21 dias encontraram-se entre os valores descritos na literatura e podem ser considerados normais. As carnes mais escuras e com menor intensidade de vermelho correspondem normalmente a carnes com pH final elevado (Muchenjea et al., 2009). Contudo, neste estudo, as correlações entre $\mathrm{pH}$ e luminosidade $(\mathrm{r}=0,03)$ e $\mathrm{pH}$ e teor de vermelho $(r=0,22)$ não foram significativas $(P>0,05)$. A menor luminosidade no dia 1 pode ser explicada pela maior capacidade de retenção de água e pela menor perda de líquidos ao meio, associadas à integridade das membranas, uma vez que a proteólise inicia-se após as 24 horas (Koohmaraie, 2002). Por outro lado, a menor intensidade de vermelho (1 e 7 dias) pode ser resultado do estado da forma química dos pigmentos heme (Mancini \& Hunt, 2005). Entretanto, Luciano et al. (2009) descrevem que a intensidade de vermelho foi reduzida ao longo do período de maturação (1 a 14 dias) e passou de valores em torno de 12 para valores inferiores a 8 e, concomitantemente, esses autores observaram reduções significativas na quantidade de pigmentos heme e aumento no percentual de metamioglobina.

Uma das condições que determina o fim da vida-deprateleira das carnes vermelhas é a descoloração por oxidação dos pigmentos heme ligados à mioglobina e ao citocromo C (Greene, 1969). Identificar as fases post mortem de maiores alterações/modificação na cor das carnes durante a estocagem ou no desenvolvimento de processos tecnológicos como a maturação são fatores de interesse para a indústria e o setor de distribuição. As propostas de MacDougal (1994) para avaliação de cor em carnes são frequentemente usadas (Lee et al., 2005; Luciano et al., 2009) e se constituem de cálculos que utilizam as informações das coordenadas luminosidade, a* e b*, tais como: o croma $\left(\mathrm{C}^{*}\right)$, o ângulo Hue $\left(H^{*}\right)$ e as diferenças globais de cor $(\Delta E)$. Os valores $\mathrm{C}^{*} \mathrm{e} H^{*}$, que são funções de $\mathrm{a}^{*} \mathrm{e} \mathrm{b}^{*}$, permitem determinar a intensidade da cor, saturação ou estimar o real escurecimento da carne, e normalmente o processo de descoloração das carnes é acompanhado por aumento nos valores $\mathrm{C}^{*} \mathrm{e} \mathrm{H}^{*}$ ao longo do tempo(Leeetal., 2005). Por outro lado, as variações globais no comportamento da cor $(\Delta E)$ são, normalmente, avaliadas pelas diferenças nas coordenadas de cor entre o tempo previsto de estocagem e o tempo inicial de avaliação (Luciano et al., 2009), sendo $\Delta E=\left(\Delta \mathrm{L}^{2}+\Delta \mathrm{a}^{2}+\Delta \mathrm{b}^{2}\right)^{0,5}$. Essa diferença de cor corresponde a valores ou índices de alterações perceptíveis ao olho humano. Conforme a escala apresentada por Prändl et al. (1994), valores de $\Delta E$ entre: 0-0,2 correspondem a alterações imperceptíveis ao olho humano; 0,2-0,5 muito pouco perceptíveis; 0,5-1,5 pouco perceptíveis; 1,5-3,0 percepções evidentes; 3,0-6,0 percepções muito evidentes; 6-12 percepção bastante clara; 12-14 facilmente perceptíveis.

As médias de $\Delta E$ para carnes de Nelore e Red Norte mostraram resultados semelhantes $(\mathrm{P}>0,05)$ com médias de $9,45 \pm 0,28$ e 9,31 $\pm 0,28$, respectivamente. Entretanto, ao comparar as médias das alterações globais ao longo do tempo de maturação (Figura 1), verificou-se que o $\Delta E_{1-7}$ diferiu significativamente $(\mathrm{P}<0,05)$ do $\Delta E_{1-14}$, que por sua vez foi semelhante $(\mathrm{P}>0,05)$ ao $\Delta E_{1-21}$. Nestes resultados, as alterações globais mais importantes foram observadas no período entre 7 e 14 dias. Luciano et al. (2009), em carne de ovinos terminados com concentrado e em pastagens, descrevem médias de $\Delta E$ que aumentam linearmente nos

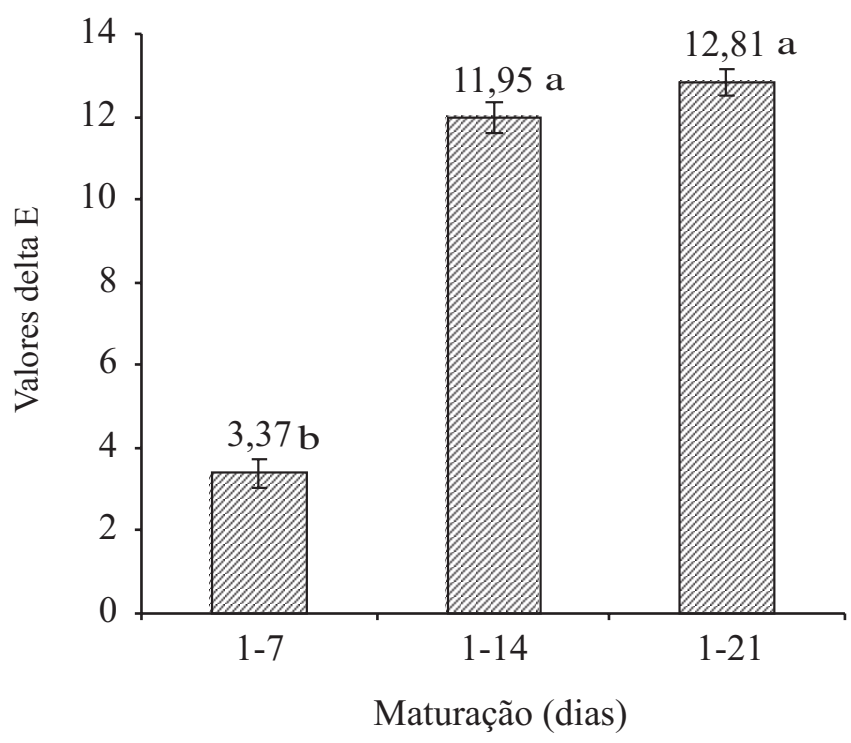

Figura 1 - Alterações globais de cor $\left(\Delta E_{1-7}, \Delta E_{1-14}\right.$ e $\left.\Delta E_{1-21}\right)$ em amostras do músculo longissimus thoracis de bovinos. 
períodos de 1 a 14 dias post mortem, entretanto esses autores não analisaram períodos posteriores a 14 dias.

Avaliando a relação entre os dados de cor, correlações positivas foram encontradas entre $a^{*}$ e $b^{*}$ nas diferentes fases da maturação, com valores de 0,77 ( $\mathrm{P}<0,01), 0,34$ $(\mathrm{P}<0,05)$ e 0,73 $(\mathrm{P}<0,01)$ aos 7,14 e 21 dias, respectivamente, indicando que a maior intensidade de vermelho foi associada à maior intensidade de amarelo e que isso pode ser atribuído ao fato de os pigmentos heme serem sensíveis à oxidação e de os pigmentos carotenoides serem anti-oxidantes (Mancini \& Hunt, 2005). Outras correlações positivas foram encontradas entre luminosidade e $\mathrm{a}^{*}$ aos 7 dias $(r=0,34$ $\mathrm{P}<0,05)$ e entre luminosidade e $\mathrm{b} *$ aos 14 dias $(\mathrm{r}=0,67$ $\mathrm{P}<0,01$ ), mostrando que quanto maior a luminosidade, nesse caso associada ao brilho da superfície das peças (menor capacidade de retenção de água), maior a intensidade de vermelho e de amarelo. Esses dados sugerem que a perda de água parece ter uma conotação positiva para o aspecto de cor. Em geral, as alterações observadas nas coordenadas de cor durante a maturação são esperadas, pois ocorrem os processos de proteólise de estruturas celulares com perda da capacidade de retenção de água (Huff-Lonergan \& Lonergan, 2005) e oxidação dos pigmentos de cor (Luciano et al., 2009).

A perda por cocção não foi afetada $(\mathrm{P}>0,05)$ pelos grupos genéticos e, quando avaliada ao longo do tempo, a média obtida aos 14 dias de maturação foi superior às médias obtidas aos 1, 7 e 21 dias. Possivelmente essas diferenças entre médias podem estar associadas à imprecisão da técnica e a variações de tempo/temperatura no processo de cocção, mas podem também retratar as alterações no sistema cárneo e na capacidade de retenção de água decorrentes da maturação (Huff-Lonergan \& Lonergan, 2005). Entretanto, a maior perda por cocção aos 14 dias não se manteve aos 21 dias.

A força de cisalhamento e o IFM são técnicas usadas para avaliar a maciez de carnes. Maior valor de força de cisalhamento corresponde a maior força necessária para romper a amostra, enquanto que valores mais elevados do índice de fragmentação miofibrilar indicam maior fragmentação da ultraestrutura da carne e, portanto, maior maciez. Neste trabalho, as médias de força de cisalhamento foram influenciadas $(\mathrm{P}<0,05)$ pelos agrupamentos genéticos, bem como as médias do índice de fragmentação miofibrilar (Tabela 3), de forma que amostras de carnes de animais Red Norte mostraram valores menores de força de cisalhamento e maior índice de fragmentação miofibrilar em comparação às de animais Nelore, demonstrando que as carnes de Red Norte foram mais macias. Comparando B. indicus e animais cruzados
$B$. taurus $\times B$. indicus outros autores relataram resultados semelhantes, Heinemann et al. (2003), em Limousin $\times$ Nelore e Nelore e Bianchini et al. (2007) em Nelore, $1 / 2$ Simental $\times 1 / 2$ Nelore, Simbrasil e Simental. De forma semelhante, Rubensam et al. (1998) descreveram que em rebanhos de animais cruzados com participação crescente do genótipo B. indicus ocorre redução na maciez da carne, o que é atribuído a diferenças na proteólise post mortem e maior atividade da calpastatina, quando comparado a B. taurus (Wheeler et al., 1990; Shackelford et al., 1994). Por outro lado, Santos et al. (2005) demonstraram que em animais cruzados (B. taurus $\times B$. indicus) é possível a obtenção de vantagens zootécnicas. Assim, raças compostas, como a Red Norte, podem apresentar benefícios do cruzamento com $B$. indicus e produzir carnes com características de maciez desejáveis.

Comparando os tempos de maturação, houve reduções significativas na força de cisalhamento ao longo do tempo de maturação (Tabela 3), de forma que as reduções entre 1 e 7 dias ( $P<0,05)$, 7 e 14 dias ( $P>0,05$ ) e entre 14 e 21 dias $(\mathrm{P}<0,05)$ foram de 1,09; 0,21 e 0,56 kg, respectivamente. $\mathrm{O}$ comportamento das curvas ajustadas da força de cisalhamento da carne dos animais dos grupos genéticos ao longo da maturação (Figura 2) mostrou que a diferença na força de cisalhamento entre as duas raças se manteve semelhante ao longo do tempo avaliado, com uma força de cisalhamento inferior no Red Norte em cerca de $0,9 \mathrm{~kg}$. As reduções na força de cisalhamento para Nelore e Red Norte aos 7 dias foram de 19 e $26 \%$, aos 14 dias de 24 e 30\%, respectivamente, e aos 21 dias de $38 \%$, para ambos os grupos genéticos. Entretanto, Heinemann et al. (2003) em Limousin $\times$ Nelore e Nelore obtiveram reduções de 28 e $29 \%$, respectivamente, em carnes maturadas por 14 dias.

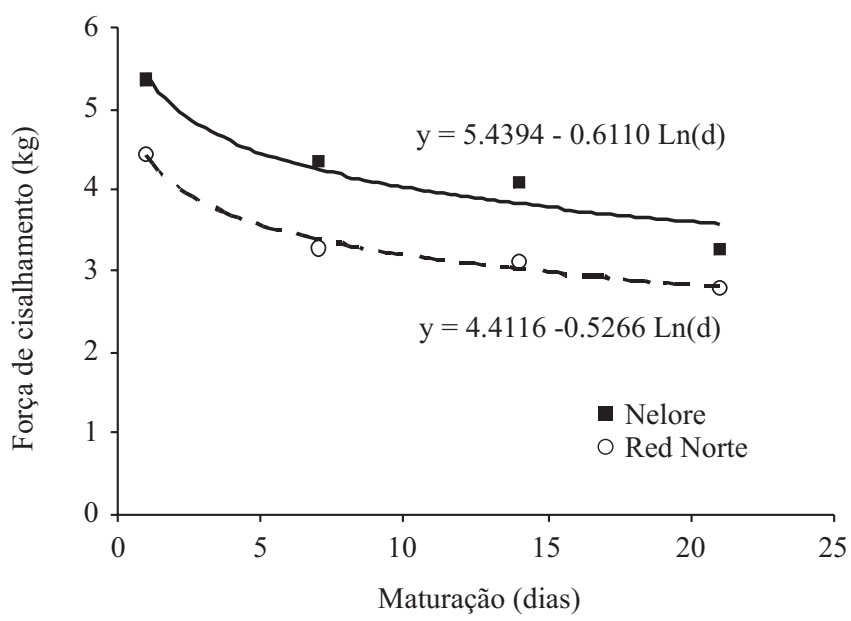

Figura 2 - Força de cisalhamento ao longo do tempo de maturação do músculo longissimus thoracis de bovinos. 
Tabela 4 - Correlações entre força de cisalhamento e índice de fragmentação miofibrilar durante a maturação

\begin{tabular}{|c|c|c|c|c|c|}
\hline & $\begin{array}{c}\text { Força de } \\
\text { cisalhamento } \\
\text { 7ํ dia }\end{array}$ & $\begin{array}{c}\text { Força de } \\
\text { cisalhamento } \\
14^{\circ} \text { dia }\end{array}$ & $\begin{array}{l}\text { Força de } \\
\text { cisalhamento } \\
21^{0} \text { dia }\end{array}$ & $\begin{array}{c}\text { Índice de } \\
\text { fragmentação } \\
\text { miofibrilar } 1^{0} \text { dia }\end{array}$ & $\begin{array}{c}\text { Índice de } \\
\text { fragmentação } \\
\text { miofibrilar } 21^{0} \text { dia }\end{array}$ \\
\hline Força de cisalhamento $1^{0} \underline{\text { dia }}$ & $0,57 * *$ & $0,58 * *$ & $0,38 *$ & $-0,27$ & $-0,28$ \\
\hline Força de cisalhamento $7 \underline{0}$ dia & & $0,71 * *$ & $0,53 * *$ & $-0,12$ & $-0,59 * *$ \\
\hline Força de cisalhamento $14^{\circ}$ dia & & & $0,74 * *$ & $-0,31 *$ & $-0,57 * *$ \\
\hline Força de cisalhamento $21^{0}$ dia & & & & $-0,25$ & $-0,48 * *$ \\
\hline Índice de fragmentação miofibrilar 10 dia & & & & & 0,22 \\
\hline
\end{tabular}

** $\mathrm{P}<0,01 ; * \mathrm{P}<0,05$.

As correlações entre os dados de força de cisalhamento avaliados nos vários momentos da maturação (Tabela 4) foram significativas e associadas positivamente, indicando que a maior maciez no dia 1 correspondeu à maior maciez aos 7, 14 e 21 dias, ainda que a correlação seja mais elevada entre a força de cisalhamento medida em períodos consecutivos (Tabela 4). Em amostras de carnes bovinas, Rubensam (1998) também encontraram correlação elevada entre força de cisalhamento obtida ao $1^{0}$ e $10^{\circ}$ dia de maturação ( $r=0,56$ - $\mathrm{P}<0,01)$.

Maior índice de fragmentação miofibrilar está correlacionado com menor força de cisalhamento e melhores notas na avaliação sensorial para a maciez (Olsson \& Parrish, 1977). Neste trabalho, as correlações entre força de cisalhamento e índice de fragmentação miofibrilar (Tabela 4) não foram significativas às 24 horas, mas o índice de fragmentação miofibrilar aos 21 dias foi negativamente correlacionado com a força de cisalhamento aos 7, 14 e 21 dias. Estes resultados sugerem que o índice de fragmentação miofibrilar reflete o efeito da proteólise, não havendo assim associação com a força de cisalhamento no dia 1, pois ela ainda não havia iniciado. Contudo, à medida que a maturação progride, o índice de fragmentação miofibrilar encontra-se mais fortemente associado com a força de cisalhamento, como resultado da ação das enzimas proteolíticas, que conduz à fragmentação das estruturas da fibra muscular e, consequentemente, à maior maciez.

De acordo com os dados, nas análises de correlações, a força de cisalhamento foi correlacionada com a coordenada a* (Tabela 5) nos dias 1, 7, 14 e 21, embora o coeficiente

Tabela 5 - Correlações entre as características de cor (1, 7, 14 e 21 dias, conforme especificado na linha) e força de cisalhamento durante a maturação

\begin{tabular}{lccc}
\hline Força de cisalhamento & Luminosidade & $\begin{array}{c}\text { Teor de } \\
\text { vermelho }\end{array}$ & $\begin{array}{c}\text { Teor de } \\
\text { amarelo }\end{array}$ \\
\hline 1 o dia de maturação & 0,06 & $-0,56 * *$ & 0,05 \\
$7 \underline{\text { o }}$ dia de maturação & $-0,10$ & $-0,41 * *$ & $-0,28$ \\
$14 \underline{\text { o }}$ dia de maturação & $-0,42 * *$ & $-0,32 *$ & $-0,32^{*}$ \\
$21 \underline{\text { o }}$ dia de maturação & 0,12 & $-0,38 *$ & $-0,27 *$ \\
\hline
\end{tabular}

** $\mathrm{P}<0,01 ; * \mathrm{P}<0,05$. tenha sido mais elevado nos dias 1 e 7 . Esses índices mostram que quanto maior a intensidade de vermelho, menor a força de cisalhamento. Assim, em carnes bovinas consideradas normais, com $\mathrm{pH}$ às 24 horas post mortem inferior ou igual a 5,8 (Mach et al., 2008), como os valores encontrados neste trabalho, é possível que uma maior intensidade de vermelho (maiores quantidades de pigmento heme ou maior capacidade de ligação ao oxigênio) seja reflexo do desenvolvimento adequado das reações bioquímicas post mortem tanto de proteólise, quanto do desenvolvimento da cor, de forma que o valor a* poderia ser um parâmetro para estimar a maciez em carnes bovinas. Entretanto, em amostras com desenvolvimento alterado das reações bioquímicas post mortem ( $\mathrm{pH}$ final maior do que 6,0), esse parâmetro pode não ser adequado para esta estimativa, embora Zhang et al. (2005) tenham descrito que carnes com altos valores de $\mathrm{pH}$ (6.10-6.79) apresentaram baixos valores para luminosidade, teor de vermelho, teor de amarelo, croma ( $\left.\mathrm{C}^{*}\right)$ e ângulo de tonalidade $\left(H^{*}\right)$, quando comparadas com carnes que mostraram valores normais de $\mathrm{pH}(5,40$ a 5,79$)$.

Os deste trabalho mostram que, utilizando carnes de animais Nelore e Red Norte, é possível conseguir ganhos importantes na maciez com períodos de maturação de 7 ou 21 dias. Por outro lado, o período de maturação de 21 dias acarreta alterações importantes na cor. Assim, é possível que a escolha por um determinado tempo de maturação esteja associada ao atributo a ser valorizado, tipo de mercado, sistema de embalagens, além do aspecto econômico.

\section{Conclusões}

Animais Red Norte apresentaram carnes com maior luminosidade e maciez em comparação a animais Nelore. A maturação melhora a maciez de carnes de animais Nelore e Red Norte aos 7 e 21 dias por reduzir a força de cisalhamento, entretanto, piora a cor, cujas alterações mais importantes são verificadas entre 7 a 14 dias. A escolha do tempo de maturação mais adequado para carnes bovinas depende do atributo a ser valorizado. 


\section{Agradecimentos}

À CAPES, ao CNPq e à FAPEMIG, pelo apoio na forma de bolsas e apoio individual à pesquisa. À EMBRAPA Pecuária Sudeste, pelo empréstimo de equipamentos e instalações. Ao Departamento de Zootecnia da Universidade Federal de Lavras, pela doação de amostras. Ao Frigorífico Frigominas e ao Serviço de Inspeção Federal, pela permissão de acesso às instalações de abate e às operações de abate e desossa. Ao Prof. Dr. Eduardo Franscisquine Delgado (Esalq/USP), pelo treinamento laboratorial. E à estudante Luisa Maria Ferreira de Sousa Oliveira, pelo apoio nas análises laboratoriais.

\section{Referências}

ABUlARACH, M.L.S.; ROCHA, C.E.; FELÍCIO, P.E. Características de qualidade do contrafilé (m. L. dorsi) de touros jovens da raça Nelore. Ciência Tecnologia de Alimentos, v.18, p.205-210, 1998.

ASSOCIATION OF OFFICIAL ANALYTICAL CHEMISTRY AOAC. Official methods of analysis. 16.ed. Arlington: AOAC International, 1995. 1025p.

BÉLTRAN, J.A.; JAIME, I.; SANTOLARIA, P. et al. Effect of stress-induced high post-mortem $\mathrm{pH}$ on protease activity and tenderness of beef. Meat Science, v.45, p.201-207, 1997.

BIANCHINI, W.; SILVEIRA, A.C.; JORGE, A.M. et al. Efeito do grupo genético sobre as características de carcaça e maciez da carne fresca e maturada de bovinos super precoces. Revista Brasileira de Zootecnia, v.36, p.2109-2117, 2007.

BRASIL. MINISTÉRIO DA AGRICULTURA. Regulamento da inspeção industrial e sanitária de produtos de origem animal. Brasília: Ministério da Agricultura, 1952. 159p.

CAÑEQUE, V.; VELASCO, S.; DÍAZ, M.T. et al. Use of whole barley with a protein supplement to fatten lambs under different management systems and its effect on meat and carcass quality. Animal Research, v.52, p.271-285, 2003.

CROUSE, J.D.; CUNDIFF, L.V.; KOCH, R.M. et al. Comparisons of Bos indicus and Bos taurus inheritance for carcass beef characteristics and meat palatability. Journal of Animal Science, v.67, p.2661-2668, 1989.

CULLER, R.D.; PARRISH J.R.; SMITH, F.C. et al. Relationship of myofibril fragmentation index to certain chemical, physical and sensory characteristics of bovine longissimus muscle. Journal of Food Science, v.43, p.1177-1180, 1978.

ERIKSSON, S.F.; PICKOVA, J. Fatty acids and tocopherol levels in M. Longissimus dorsi of beef cattle in Sweden - a comparison between seasonal diets. Meat Science, v.76, p.746-754, 2007.

FERREIRA, A.M.; CARDOSO, R.M. Clima e reprodução da fêmea bovina. Coronel Pacheco: EMBRAPA-CNPGL, 1993. $35 p$.

GAMA, L.T. Melhoramento genético animal. Lisboa: Escolar Editora, 2002. 306p.

GORNALL, A.G.; BARDAWILL, C.J.; MAXIMA, M.D. Determination of serum proteins by means of biuret reaction. Journal of Biological Chemistry, v.177, p.751-766, 1949.

GREENE, B.E. Lipid oxidation and pigment changes in raw beef. Journal of Food Science, v.34, p.110-113, 1969.

HEDRICK, H.B.; PATERSON, J.A.; MATCHES, A.G. et al. Carcass and palatability characteristics of beef produced on pasture, corn silage and corn grain. Journal of Animal Science, v.57, p.791-801, 1983.
HEINEMANN, R.J.B.; PINTO M.F.; ROMANELLI, P.F. Fatores que influenciam a textura da carne de novilhos Nelore e cruzados Limousin-Nelore. Pesquisa Agropecuária Brasileira, v.38, p.963-971, 2003.

HUFF-LONERGAN, E.; LONERGAN, S.M. Review. Mechanisms of water-holding capacity of meat: The role of postmortem biochemical and structural changes. Meat Science, v.71, p.194-204, 2005

INSTITUTO BRASILEIRO DE GEOGRAFIA E ESTATÍSTICA IBGE. Produção da pecuária. Disponível em: <www.ibge.gov.br/ home/presidencia/noticias/noticia_visualiza.php?id_noticia =759\&id_pagina $=1.2007>$. Acesso em: 15/10/2007.

KANAWA, R.; JI, J.R.; TAKAHASHI, K. Inactivity of ì-calpain throughout postmortem aging of meat. Journal of Food Science, v.67, p.635-638, 2002.

KOOHMARAIE, M.; KENT, M.P.; SHACKEIFORD, S.D. et al. Meat tenderness and muscle growth: is there any relationship? Meat Science, v.62, p.345-352, 2002.

LEE, S.; DECKER, E.A.; FAUSTMAN, C. et al. The effects of antioxidant combinations on color and lipid oxidation in $n-3$ oil fortified ground beef patties. Meat Science, v.70, p.683-689, 2005.

LUCIANO, G.; MONAHAN, F.J.; VASTA, V. et al. Lipid and colour stability of meat from lambs fed fresh herbage or concentrate. Meat Science, v.82, p.193-199, 2009.

MACDOUGAL, D.B. Colour meat. In: PEARSON, A.M.; DUTSON, T.R. (Eds.). Quality attributes and their measurement in meat, poultry and fish products - Advances in Meat Research Series. London: Blackie Academic \& Professional, 1994. v.9, cap.3, p.79-93.

MACH, N.; BACH, A.; VELARDE, A. et al. Association between animal, transportation, slaughterhouse practices, and meat pH in beef. Meat Science, v.78, p.232-238, 2008.

MANCINI, R.A.; HUNT, M.C. Review: Current research in meat color. Meat Science, v.71, p.100-121, 2005.

MARIANTE, A.S.M.; MCMANUS, C.; MENDONÇA, J.F. Country report on the state of animal genetic resource Brazil. Brasília: Embrapa Genetic Resource and Biotechnology, 2003. 92p.

MOREIRA, F.B.; SOUZA, N.E.; MATSUSHITA, M. et al. Evaluation of carcass characteristics and meat chemical composition of Bos indicus and Bos indicus x Bos taurus crossbred steers finished in pasture systems. Brazilian Archives of Biology and Technology, v.46, p.607-614, 2003.

MUCHENJEA, V.; DZAMAC, B.K.; CHIMONYOA, M. et al. Some biochemical aspects pertaining to beef eating quality and consumer health: a review. Food Chemistry, v.112, p.279-289, 2009.

MUROYA, S.; NNAKAJIMA, I.N.; CHIKUNI, K. Difference in postmortem degradation pattern among troponin $\mathrm{T}$ isoforms expressed in bovine longissimus, diaphragm, and masseter muscles. Meat Science, v.72, p.245-251, 2006.

NATIONAL RESEARCH COUNCIL - NRC. Nutrients requeriments of beef cattle. 7.ed. Washington, DC, 2000. 244p.

NEATH, K.E.; DEL BARRIO, A.N.; LAPITAN, R.M et al. Difference in tenderness and $\mathrm{pH}$ decline between water buffalo meat and beef during postmortem aging. Meat Science, v.75, p.499-505, 2007.

OLSSON, D.G.; PARRISH J.R., F.C. Relationship of myofibril fragmentation index to measures of beefsteak tenderness. Journal of Food Science, v.42, p.506-509, 1977.

PÖSÖ, A.R.; PUOLANNE, E. Carbohydrate metabolism in meat animals. Review. Meat Science, v.70, p.423-434, 2005.

PRÄNDL, O.; FISCHER, A.; SCHMIDHOFER, T. et al. Tecnologia e higiene de la carne. Zaragoza: Acribia, 1994. 854p.

PRIOLO, A.; MICOL, D.; AGABRIEL, J. Effects of grass feeding systems on ruminant meat colour and flavour: a review. Animal Research, v.50, p.185-200, 2001.

PURCHAS, R.W. An assessment of the role of $\mathrm{pH}$ differences in determining the relative tenderness of meat from bulls and steers. Meat Science, v.27, p.120-140, 1990. 
RODRIGUES, V.C.; ANDRADE, I.F. Características físico-químicas da carne de bubalinos e de bovinos castrados e inteiros. Revista Brasileira de Zootecnia, v.33, p.1839-1849, 2004.

ROSSATO, L.V.; BRESSAN, M.C.; RODRIGUES, E.C. et al. Composição lipídica de carne bovina de grupos genéticos taurinos e zebuínos terminados em confinamento. Revista Brasileira de Zootecnia, v.38, p.1841-1846, 2009.

ROSSATO, L.V.; BRESSAN, M.C.; RODRIGUES, E.C. et al. Parâmetros físico-químicos e perfil de ácidos graxos da carne de bovinos Angus e Nelore terminados em pastagem. Revista Brasileira de Zootecnia, v.39, p.1127-1134, 2010.

RUBENSAM, J.M.; FELICIO, P.E.; TERMIGNONI, C. Influência do genótipo Bos indicus na atividade de calpastatina e na textura da carne de novilhos abatidos no sul do Brasil. Ciência e Tecnologia de Alimentos, v.18, p.405-409, 1998.

SANTOS, S.A.; SILVA, R. A.M.S.; COMASTRI-FILHO, J.A. et al. Desempenho de bezerros Pantaneiros, Nelore e cruzados, criados no Pantanal, Brasil. Archivos de Zootecnia, v.54, p.501-508, 2005.

SHACKELFORD, S.D.; KOOHMARAIE, M.; CUNDIFF, L.V. et al. Heritabilities and phenotypic and genetic correlations for bovine post rigor calpastatin activity, intramuscular fat content, Warner-Bratzler shear force, retail product yield, and growth rate. Journal of Animal Science, v.72, n.4, p.857-863, 1994.

SILVEIRA, I.D.B.; FISCHER, V.; SOARES, G.J.D. Relação entre o genótipo e o temperamento de novilhos em pastejo e seu efeito na qualidade da carne. Revista Brasileira de Zootecnia, v.35, p.519-526, 2006.

STATISTICAL ANALYSES SYSTEMS - SAS. User's guide: statistic. Cary: SAS Institute, 2004. 176p.
VAZ, F.N.; RESTLE, J.; FEIJÓ, G.L.D. et al. Qualidade e composição química da carne de bovinos de corte inteiros ou castrados de diferentes grupos genéticos Charolês x Nelore. Revista Brasileira de Zootecnia, v.30, p.518-525, 2001.

VIEIRA, C.; CERDEÑO, A.; SERRANO, E. et al. Breed and ageing extent on carcass and meat quality of beef from adult steers (oxen). Livestock Science, v.107, p.62-69, 2007.

VOISINET, B.D.; GRANDIN, T.; O'CONNOR, S.F. et al. Bos indicuscross feedlot cattle with excitable temperaments have tougher meat and a higher incidence of borderline dark cutters. Meat Science, v.46, p.367-377, 1997.

WHEELER, T.L.; KOOHMARAIE, M.; SHACKELFORD, S.D. Standardized Warner-Bratzler shear force procedures for meat tenderness measurement. Clay Center: Roman L. Hruska U. S. MARC. USDA, 1995. 7p.

WHEELER, T.L.; SAVELL, J.W.; CROSS, H.R et al. Mechanisms associated with the variation in tenderness of meat from Brahman and Hereford cattle. Journal of Animal Science, v.68, p.4206-4220, 1990.

WHIPPlE, G.; KOOHMARAIE, M.; DIKEMAN, M.E. et al. Evaluation of attributes that affect longissimus muscle tenderness in Bos taurus and Bos indicus cattle. Journal of Animal Science, v.68, p.2716-2728, 1990.

WILLIAMS, J.E.; WAGNER, D.J.; WALTERS, L.E. et al. Effect of production systems on performance, body composition and lipid and mineral profiles of soft tissue in cattle. Journal of Animal Science, v.57, p.1020-1027, 1983.

ZHANG, S. X., FAROUK, M. M., YOUNG, O. A. et al. Functional stability of frozen normal and high $\mathrm{pH}$ beef. Meat Science, v.69, p.765-772, 2005. 